\title{
A Comparative Life Cycle Investment Analysis for Biopower Diffusion in Rural Nigeria
}

\author{
June Levi-Oguike* * Diego Sandoval and Etienne Ntagwirumugara
}

check for updates

Citation: Levi-Oguike, J.; Sandoval, D.; Ntagwirumugara, E. A Comparative Life Cycle Investment Analysis for Biopower Diffusion in Rural Nigeria. Sustainability 2022, 14 , 1423. https://doi.org/10.3390/ su14031423

Academic Editor: Dino Musmarra

Received: 12 October 2021

Accepted: 28 December 2021

Published: 26 January 2022

Publisher's Note: MDPI stays neutral with regard to jurisdictional claims in published maps and institutional affiliations.

Copyright: (C) 2022 by the authors. Licensee MDPI, Basel, Switzerland. This article is an open access article distributed under the terms and conditions of the Creative Commons Attribution (CC BY) license (https:// creativecommons.org/licenses/by/ $4.0 /)$.

\author{
African Centre of Excellence in Energy for Sustainable Development (ACE-ESD), Nyarugenge, Kigali, Rwanda; \\ dsandovalv@gmail.com (D.S.); etienne.ntagwirumugara@gmail.com (E.N.) \\ * Correspondence: jlevioguike@gmail.com
}

\begin{abstract}
This paper adopts the Life Cycle Investment (LCI) approach proposed by Farinha et al. to assess project viability based on the maintenance and operational efficiency of a proposed biopower plant over its useful economic life. The adoption of ISO 55000:2014, its guidance on management and maintenance policies for physical assets, and its contribution to the achievement of sustainable development goals on clean and affordable energy (SDG7) remain relevant for investment decisions regarding waste-to-energy technology systems. Using the parameters defined in a previous biopower feasibility study for Nigeria, the LCI approach is applied to show the change in project profitability over the estimated useful life of the plant, where availability is altered, based on maintenance downtime and overall operational efficiency. The results show positive movement in operational efficiency between $85-91 \%$, which correlates with increased profitability in the same period. The project's profitability and return on investment is revised downward from $29 \%$ to $8 \%$ based on the initial availability adjustment, and the changes in derived profit based on plant availability support the argument in favor of operational efficiency and structured maintenance policies as key performance and investment viability indicators, which ultimately impact the total cost of ownership. The results are also interpreted using Pareto Principles for emphasis. The ultimate goal is to encourage due attention and diligence in relation to latent factors which often erode the perceived benefits of viable projects after completion and potentially hamper future investment, specifically in the broader sub-Saharan African waste management context.
\end{abstract}

Keywords: UNSDGs; waste; energy; biopower; sustainability; LCC; LCI

\section{Introduction}

Rural electrification rates in developing countries remain considerably low, with an estimated 1.6 billion people still living without access to electricity [1]. Estimates for Nigeria's total installed and operational capacity are pegged at 12,310 MW and $7788 \mathrm{MW}$, respectively, with approximately $3750 \mathrm{MW}$ available annually [2]. These metrics are for 28 on-grid power plants plagued with gas and water shortages, and frequent breakdowns due to commercial and technical grid constraints [2].

The total demand for power is expected to increase by almost $27 \%$ in developing countries, from 19,562 TWh to 26,761 TWh between 2012 and 2025 [1], with global capacity projections of up to $8370 \mathrm{GW}(2025)$, about $70 \%$ of which would be attributable to enhanced capacity in developing countries [3].

The Transmission Company of Nigeria (TCN) forecasts electricity demand to expand at a rate of $6 \%$ up until 2035, and with universal access targets for 2030 and roughly 20 million households still living without energy access [4]. Nigeria's current and future energy demand will remain suppressed. This is mostly due to poor electricity supply infrastructure and networks, with attendant illiquidity and significant debt within the energy supply industry [2]. 
Ezennaya et al. [5] also predicts an electricity demand growth factor of $1.9 \times 103 \mathrm{MWh}$ due to technological and economic expansion, and renewable energy (RE) sources are expected to contribute to approximately $10 \%$ of required energy cover.

Biomass energy remains a viable RE resource, and with Nigeria's biomass potential estimated to be around 3.2 EJ (2010), 5.5 EJ (2020), and 29.8 EJ (2050), it provides a viable supplement to cover suppressed energy demand. The popular biomass sources remain as agricultural and livestock wastes, municipal solid wastes (MSW), and forest residues; in order to determine the viability of biomass feedstock for power generation, factors such as the nature of feedstock and its supply, waste conversion processes, and the proposed technology for power generation must be considered.

MSW is in focus because it empirically possesses high capacity factors and is considered an economic source of electricity [6]. The proper management and conversion of MSW to energy still remains a challenge in most developing countries, and in view of current global public health challenges, the import for rural populations in particular in terms of health and general wellbeing is evident; rampant dumping, inadequate collection, and uncontrolled burning of solid wastes remain an unfortunate norm $[7,8]$.

In Nigeria, MSW is generated at an average rate of 0.49 to $0.56 \mathrm{~kg} \mathrm{MSW} / \mathrm{cap} /$ day; this is expected to rise in urban areas by 2025 to $0.80 \mathrm{~kg}$ MSW/cap/day, translating to almost 100,000 tons of MSW / day [5]. Waste-to-Energy (WtE) systems are therefore projected to provide about $0.7-1.7 \%$ of total projected energy supply and represent up to $9.8-26.2 \%$ of indicative energy consumption by 2025 [5].

General MSW thermal treatment processes include incineration, gasification, liquefaction, pyrolysis, curing, and direct combustion [9]. However, only a few of these have proved adequate and economically viable for African cities in the near to medium term, as conventional waste treatment technologies are often technically beyond the capacity of most local and regional municipalities and are therefore challenging to implement. WtE technologies are also costly, and considering the modest economic capacities of the populace, open dumping and burning of wastes remain preferred 'models' for waste management [10].

This provides opportunities for the implementation of decentralized "waste" management $[11,12]$ and electrification systems in order to reduce regional disparity in rural and remote areas, and equally provides the enhanced reliability of energy supply and potential income generation streams, especially for informal waste actors from the use of local resources, as trash is generally homogenous. Centralized energy supply systems are losing popularity, due to fossil fuel depletion and environmental concerns, insecurities surrounding energy transport infrastructure, and investors hedging their risk exposure through the deployment of smaller-scale, modular generation, and transmission energy systems $[1,13]$. Decentralized waste conversion technology has therefore been proffered as a viable route, using locally available resources for the electrification of rural and remote areas.

Biomass power is expected to be connected to both national and minigrids through decentralized power stations connected to modular power line networks; this will service several households, buildings, or machinery, thereby increasing energy access for rural communities [14].

The funding deficit, however, remains a core challenge for solid waste management in Nigeria, considering related waste volumes. This deficit is enhanced by systemic inadequacies and inefficiencies, especially in operational capacity, as was observed in Umuahia, a South-Eastern Nigerian city with over 1.2 million people; about 50 metric tons of waste is generated daily, with a total waste collection capacity of 76 garbage bins [15].

The Nigerian economy, following the severe aftermath of the global pandemic, has slid into economic recession with attendant unemployment and an overall decline in the standard of living and wellbeing of people. Rural communities in particular require focused intervention to bridge local and regional disparities, and to equally manage the impact of rising populations with increased rural-urban migration rates.

In terms of biopower investment and adoption, investor and consumer willingness to adopt this energy conversion strategy has been linked to the level of education and 
sensitization among intended users, alongside robust and well executed tax deduction and energy subsidy schemes, which include production tax credits (PTCs) $[16,17]$ among others. Biomass power plant investments have mostly been successful where supportive state and federal RE electricity policies exist, and are implemented rationally and objectively to maximize its inherent benefits for both current and future energy demand. In sufficiently justifying the need for biomass-based energy and outlining its benefits for rural and urban poor communities, which are often marginalized, the subsequent challenge remains hinged on bridging the finance gap to attract private funds in facilitating and actualizing inherent $\mathrm{WtE}$ benefits. Therefore, the question of how to successfully commercialize and disseminate this energy source through enhanced private investment persists.

The basis of investment, techno-economic, or technology assessments are often to determine the value of technical efficiency and infrastructure investment required to fulfill project objectives. This often ignores significant elements which impact revenue streams and the entire value of a given project at a future date. Factoring in the time value of costs or 'variable investments' and operational efficiencies allows for a comprehensive evaluation of the project in cognizance of the uncertainty and significant financial risk of investment. This paper therefore seeks to highlight the significance of maintenance downtime and the resulting availability of the plant as a key element in investment consideration and project profitability, based on established LCCA results in the focal region.

It introduces the concept of Life Cycle Investment (LCI), especially for physical assets employed in industrial processes, in line with the International Organization for Standardization (ISO) 55000:2014 asset management system and erstwhile Publicly Available Specification (PAS) 55. The standard remains focused on sustainability principles, and provides guidelines on the management of assets through the entire life cycle.

This study is relevant, as Waste-to-Energy initiatives have often been ignored and criticized as lacking commercial viability, particularly in contrast to solar and hydro power modular systems, and have also been deemed technically and financially demanding due to the complexities in the sorting and separation of waste matter. However, the inherent benefits for the environment and overall sustainability objectives cannot be conscientiously overlooked. The overall objective remains to provide guidance and a basis for enhanced investment in terms of adequately assessing the inherent complexities of proposed ventures in politically and financially risky climes, such as Nigeria's and consequently boost private participation in the general African waste valorization domain.

\section{Background and Literature Overview}

The market for WtE systems is expected to grow by roughly 79\% to about USD 29.2 billion between 2012-2022 [6], another growth estimate forecast puts the figure at around USD 80.6 billion [6]. WtE systems are equally projected to treat a minimum of 261-396 million tons of waste annually by 2022, with a total estimated output of 283-429 TWh of power [6].

The specific WtE conversion process or technology is equally imperative to operational efficiency or availability. Biomass gasification has been empirically observed to possess two times the effectiveness in reducing GHG emissions over other RE technologies, with lower unit costs of electricity, and has been posited as a strategically viable option for rural electrification [6]. It is also deemed suitable for Village Energy Security Programmes (VESP) and Remote Village Electrification (RVE), and is equally an efficient energy recovery method for industrial purposes, as it produces less harmful effluents, which often pose severe environmental hazards [6].

Small biomass gasification power plants provide a competitive way to convert diverse, biomass waste to syngas for combined heat and power (CHP) generation and certain gasification power plants have been successfully commercialized, with electrical and cogeneration efficiencies of about $20-80 \%$, with $500-1000 € / \mathrm{kWe}$ estimated global capital cost [18].

This is evidenced in the Entrade Energiesystems E3 micro-scale biomass CHP plant in Cheshire, United Kingdom, which surpassed 1000 h of operation with minimal human inter- 
ference in 2015 (http: / / www.renewableenergyfocus.com/view/42637/world-s-smallestbiomass-power-plant-using-biomass-gasification-passes-1000-hours / (accessed on 5 October 2021)). The gasification technology provides continuous baseload power at micro scale to generate decentralized energy on-site, which boosts the competitiveness of small-scale baseload energy, and a maintenance-free, modularized CHP can be adapted for local use. The E3 system overcame the challenge of $24 / 7$ maintenance due to regular breakdowns by producing almost no tar, and runs efficiently with roughly $15 \mathrm{~min}$ of maintenance required weekly (http:/ / www.renewableenergyfocus.com/view/42637/world-s-smallest-biomasspower-plant-using-biomass-gasification-passes-1000-h (accessed on 5 October 2021)). The upgraded E4 model (https:/ / bioenergyinternational.com/technology-suppliers/entradeshowcases-high-performance-micro-biomass-power-plant-at-hannover (accessed on 5 October 2021)) was introduced in 2018, and uses waste to produce high-quality syngas, which powers an internal combustion engine and supplies electricity, heat, or cooling, as required.

The E4 model is considered "the world's first modular, series-produced, patented, fully automatic biomass power plant for grid-connected and off-grid power generation" (https:// bioenergyinternational.com/technology-suppliers/entrade-showcases-high-performancemicro-biomass-power-plant-at-hannover (accessed on 5 October 2021)). Each individual E4 power plant has a generation output of $50 \mathrm{kWe}$ and a nominal heat output of $120 \mathrm{kWth}$, and can be fully operational on a turnkey basis within 2 days (https:/ / bioenergyinternational. com/technology-suppliers/entrade-showcases-high-performance-micro-biomass-powerplant-at-hannover (accessed on 5 October 2021)). The electric power generated from the system is deemed competitive with or without subsidies compared to other alternatives, and can be used locally as a stand-alone system or fed-in to the national grid. The individual plants can be connected to form larger units of up to $5 \mathrm{MW}$, and approximately 150 plants have been successfully deployed in 9 different countries worldwide, as of 2018 . The E4 system's dimensions are $186 \mathrm{~cm}$ in length and $156 \mathrm{~cm}$ in width, and can be shipped globally by air freight.

From the above, it is evident that the developed world has sufficiently produced and continues to innovate energy solutions for enhanced well-being and efficiency. The "how? "question in investment terms posited earlier, however, has traditionally been answered by Life Cycle Costing (LCC) methods, as it determines the "probabilistic interdependence of macroeconomic variables over time" [19] and provides a "cradle-to-grave" assessment [18] of the environmental or associated costs of a process, product, or activity by accounting for physical and material resources required to deliver output. It is generally adopted within engineering and business communities, and consists of adding all relevant and related costs over a specified period of use, subtracting the terminal value, and ultimately adjusting for inflation $[20,21]$. This analysis is usually sufficient in economies where certain variables can be predicted with relative accuracy. The economic and political climate of most African countries, however, begs a different approach to ultimately minimize long-term investor exposure and boost economic activity and development in the proposed sectors.

The goal of any LCC analysis is to determine two significant economic metrics, Life Cycle Costs (LCC) and Levelized Cost of Energy (LCOE), for a given biopower pathway [22]. According to $\mathrm{Li}$ [23], the LCC of a power plant encompasses the total costs generated throughout the plant's useful life and provides insights into the "lowest long-term cost of ownership", as the expenses that would normally occur during each stage of the project and the concept of present values [16] are considered objectively.

The most suitable method for evaluating the profitability of a potential investment is defined by the project's aims and objectives. In this case, the objective is to present biomass, and specifically decentralized systems, as attractive alternatives to solar and small hydropower RE systems, which currently enjoy commercial popularity. Potential private operators and investors remain focused on maximizing profit, and therefore, this study tests an addendum to traditional LCC methods postulated in a previous study to guide investment decisions. 
The literature on LCC methodology is vast, however, several authors such as Spickova and Myskova [24] have identified the significance of maintenance and operation costs as part of the main components of an LCC analysis, which seeks to ensure that investment objectives are optimized without sacrificing performance.

Kianian et al. [25] emphasize the importance of quality, productivity, and availability as three key performance metrics which are often overlooked in LCC computations, but remain pertinent in determining the Overall Equipment Efficiency (OEE) measure. Bengtsson and Kurdve [26] suggest that an asset must be analyzed from an investment perspective, and that a low LCC for a project does not automatically imply a significant Life Cycle Profit (LCP); therefore, the LCC must be assessed in tandem with the productivity or project output.

Ljiljana, Dragutin, and Zelimir [27] state that maintenance management was the precursor to asset management, which remains focused on maximizing the life of physical assets and emphasized its importance in the overall performance of a given entity. This is supported by Katicic et al. [27], who emphasized the importance of asset management as evolving from a maintenance focused culture, and states the relevance of asset governance to the implementation of the ISO 55000 standards.

Stimie and Vlok [28] developed a strategy for early failure detection to assist asset managers. The "Physical Asset Management Strategy Execution Enforcement Mechanism" (PAMSEEM)" provides a system for feedback, decision-making, and execution strategy, all centered around the management of physical assets through their respective life cycles.

The relevance of an asset's operations, management, and entire life cycle to the overall investment, future operational, and related costs are highlighted in Eicher's [29] work, where the imperative of considering the operating life of a given physical asset before its construction or development is equally emphasized.

Maintenance performance indicators are assessed in terms availability, mean repair times and the time between failures, where the asset operates optimally and these metrics are used as tools to determine the correlation between the maintenance schedule, policies, and economic benefit or Return on Investment (ROI) [30,31].

Traditional LCC analyses have been criticized for failing to include income from output or production activity and overall investment in maintenance. By recognizing these factors, the potential investor is able to determine core strategies to optimize plant availability in this case and the overall performance and life of physical assets employed in production activity; this ultimately supports overall investment profitability [32].

\section{Materials and Methods}

This paper adopts the Life Cycle Investment (LCI) approach developed by Farinha et al. [32] to analyze a plant's LCC through its financial life cycle using econometric models. The initial investment in a physical asset, such as a power plant, involves an outflow of economic benefit or resources, and the authors argue that the term 'investment' is erroneously used since an outflow occurs; whereas the financial and related resources employed in the maintenance of the same asset required to deliver economic value are deemed costs. It is this contrast that the LCI analysis bridges; it enables the evaluation of maintenance schedules and structures in terms of the overall effect on the plant's medium to long-term productivity and related profitability; this is especially prevalent in industrial processes or services undertaken for public benefit, such as electricity.

The plant's availability is deemed paramount to the entire analysis, and the key performance indicators within the context of maintenance policy and schedules are determined based on the time to repair and the maximum availability.

This paper therefore adapts the LCI approach to the feasibility study conducted by Oyegoke and Jibiril [33] for a proposed $5 \mathrm{MW}$ biopower plant in Nigeria. The study outcomes are evaluated to a limited extent, with emphasis on the revised profitability outcome based on the LCI analysis.

A power plant will normally start and remain in operation over an extended period, which inherently involves long-term costs that must be accounted for. The present value 
(PV) of future costs is determined and discounted at prevailing inflation and interest rates $(R i)$. In this context, the LCC of the plant is the sum of the present value of total costs $(F C i)$ over the plant's estimated life, as expressed in Equation (1) below:

$$
\mathrm{PV}=\sum_{i=0}^{n} \frac{F C i}{(1+R i) i}
$$

The lifetime associated costs of developing the power plant include those related to strategic decisions, purchase of plant and office equipment, installation, and operating costs, alongside routine maintenance, commission, and decommissioning costs, which would normally be aggregated.

In contrast to the traditional LCC methodology, Farinha et al. [31] argue for a distinction between project investments and costs, stating that initial costs should be deemed initial investments, while secondary costs should be "variable investments".

The LCI approach adopts a performance indicator for maintenance services at the plant, as the sum of plant processes and productivity metrics are dependent on this factor; this is ultimately captured by the operational efficiency rate or 'availability'. Farinha et al. [31] postulates a direct correlation between profit or benefits and availability, and states that profit calculations must recognize equipment downtime due to routine maintenance; this gives rise to a "Mean Wait Time $(M W T)$ " and a "Mean Time To Repair (MTTR)". The functional time, i.e., when plant equipment functions optimally, would be represented by a "Mean Time Between Failures (MTBF)". A low MTTR would signal greater operational efficiency or "maximum availability", and would ultimately bear a significant impact on the calculated profits which would guide the final investment decision based on the evaluation.

Operational efficiency or availability is therefore modelled as follows:

$$
E i=\frac{M T B F i}{M W T i+M T T R i+M T B F i}
$$

$i$, represents the time period to the $i$ th year, while the period of inefficiency, unavailability, or non-production is expressed below:

$$
U_{i}=P i^{*}\left(1-E_{i}\right)
$$

$P i$ denotes the profit or project benefit.

Adapting the LCI theorem to the standard LCC model, the initial and variable maintenance investments are modelled in Equation (4) to derive a "global result" or total performance indicator $\left(T P_{n}\right)$ as follows:

$$
\sum_{i=0}^{n} \frac{P i * E i}{\left(1+R_{i}\right) i}-\sum_{i=0}^{n} \frac{F i}{\left(1+R_{i}\right) i}-\sum_{i=0}^{n} \frac{M i}{\left(1+R_{i}\right) i}-\sum_{i=0}^{n} \frac{U i}{\left(1+R_{i}\right) i}+\sum_{i=0}^{n} \frac{I i}{\left(1+R_{i}\right) i}
$$

where, for the year $i$ :

$\mathrm{P} i$ is the value of benefit or profit

$E_{i}$ is the efficiency or availability

$F i$ is the value of functional time

$M i$ is the value of routine maintenance

$U_{i}$ is the value of non-production or unavailability, and

$I i$ is the value of the power plant

Oyegoke and Jubiril [33] developed a detailed feasibility study for the construction of a $5 \mathrm{MW}$ biopower plant in Nigeria, estimated to produce $130 \mathrm{MWh}$ with an initial investment cost of USD 89 million and USD 81 million in operating costs. In their analysis, the duration of power supply, heating value, and energy generation were used to determine the cost of equipment. The plant's profitability was evaluated based on the total capital invested and operation costs, and was eventually deemed a worthwhile investment to boost development in the Nigerian economy. 
Based on the above, the plant was deemed to realize a total net profit of USD 26 million, with an estimated net present worth or benefit of USD 191 million, and a 29\% return on investment. The relevant model parameters and estimates derived from their study and tested in the LCI analysis are summarized in Table 1 below:

Table 1. Parameters for LCI Analysis.

\begin{tabular}{cc}
\hline Plant Capacity & $5 \mathrm{MW}$ \\
\hline Initial Investment Cost & US\$89million \\
\hline Operating Cost & US\$81million \\
\hline Estimated Days of Operation & $355 ;$ adjusted at $85 \%$ and $91 \%$ \\
\hline Discount Rate & US\$191million \\
\hline Benefit (Net Present Worth) & $20 \%$ of Investment Cost \\
\hline Maintenance and Repair Cost & 25 years \\
\hline Plant Life &
\end{tabular}

\section{Results and Discussion}

From Table S1 (see Supplementary Materials), the benefit which represents the net present value of future flows expected from the plant's operations, from inception to the end of its 25-year useful life, and duly discounted based on Oyegoke and Jibril's [33] detailed analysis, is deducted from the accumulated total discounted costs to derive a "global result" or total performance indicator, which essentially represents the plant's profitability for the defined period at specific availability or efficiency rates.

From the project's defined parameters and investment estimates, it was observed that at $85 \%$ operational efficiency or availability (which is interpreted as minimal MWTs and MTTRs, with maximum MTBFs), positive total performance is observed from the 3rd to the 4th year of the plant's operational life. This translates to the plant operating profitably for approximately $8 \%$ of its useful economic life.

Interpreting this based on Oyegoke et al. [33], if the plant is deemed to be in operation for 355 days, and is only available for $85 \%$ of that time, due to MWTs or MTTRs and other maintenance, related challenges such as unavailable technicians or inadequate spare parts, it is therefore operationally efficient for approximately 302 days only. This equally impacts the decision to invest or execute the project, as a recomputed return on investment (ROI) based on the LCI outcome is 8.2\% only as against Oyegoke et al.'s [33] 29\%.

In Table S2 (see Supplementary Materials), the plant's availability is increased to 91\% and this boosts profitability significantly, from the 3rd to 18th years of operation. The return on investment rises proportionately, and this is illustrated in Figures 1 and 2, where the trendline shows the proportion of operational profit based on the defined availability rates.

From Figure 1, the plant is shown to be profitable for only about $8 \%$ of its useful life, while in Figure 2, this rises significantly to approximately $64 \%$ based on operational efficiency at $91 \%$. The additional 14 -year profitability gained at $91 \%$ efficiency represents an average $56 \%$ increase in total performance by simply increasing availability or operational efficiency due to more detailed attention to a structured maintenance regime.

The 'Pareto Principle' encompasses cause and effect concepts under the ' $80 / 20$ ' rule, where at least " 80 percent of problems can be traced to 20 percent of the causes" (https: //www.mindtools.com/pages/article/newTED_01.htm (accessed on 7 October 2021)). Adapting this principle to the concept of LCI and the total performance indicators derived, it can then be said that 80 percent of the benefit or profit is derived from 20 percent of the variables; in this case, it is the impact of maintenance on availability and overall profitability. Pareto principles encompass causality and impact, and therefore allows for the prioritization of strategic responses or solutions to improve the activity, process, or product in focus. 


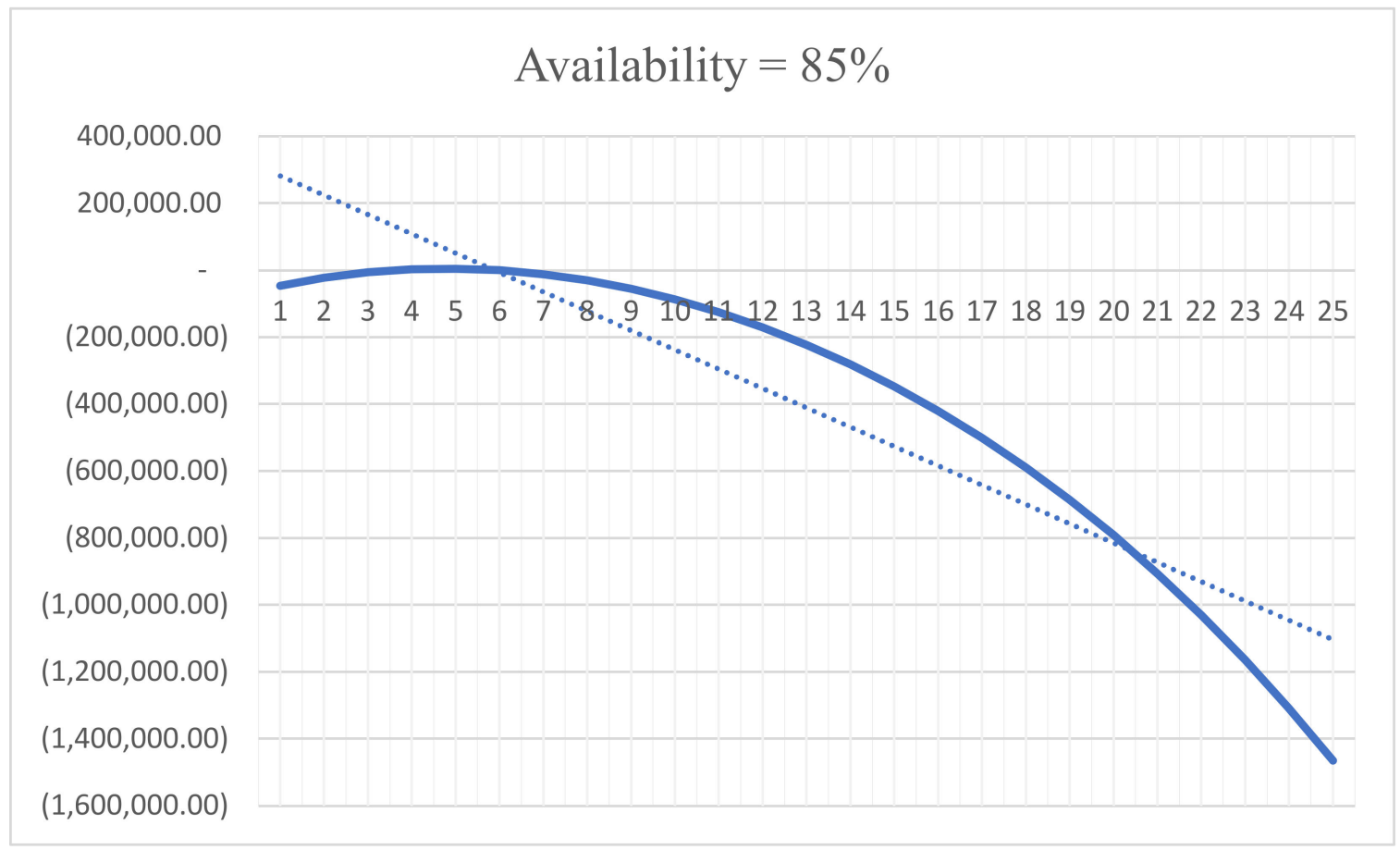

Figure 1. Total Performance Indicator at 85\% Plant Availability.

$$
\text { Availability }=91 \%
$$

$150,000.00$

$100,000.00$

$50,000.00$

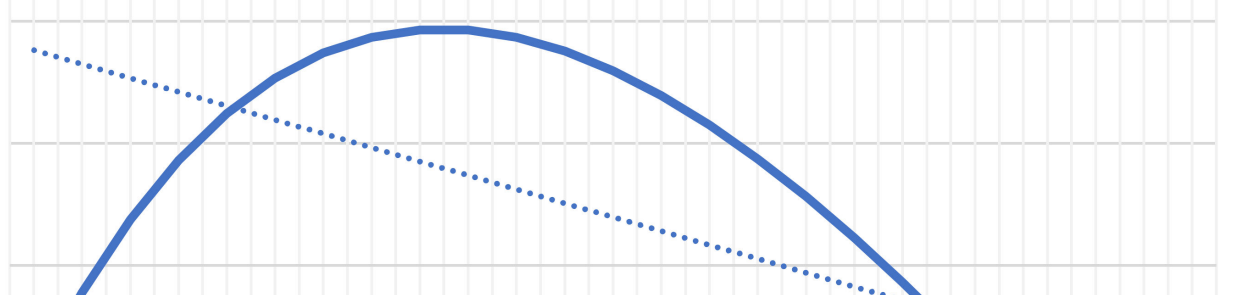

$(50,000.00)$

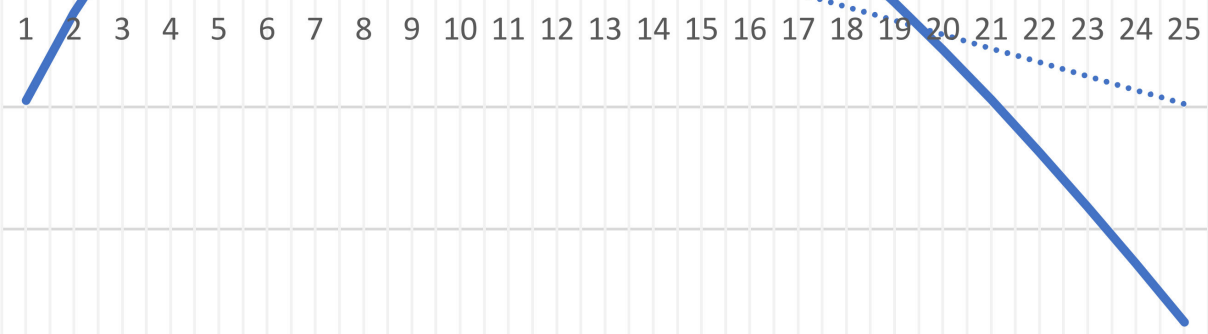

$(150,000.00)$

Figure 2. Total Performance Indicator at 91\% Plant Availability.

The trend in Figures 1 and 2 suggest smaller profits or benefit as the plant nears the end of its economic useful life, which could be interpreted in terms of aging machinery or equipment and other future unknowns hampering total availability, benefit, and performance.

Although pareto principles are traditionally applied to determine a problem and/or its effects on a given activity or process, in this context, it is used to support and show the impact of an often overlooked or minor but critical variable on the plant's total performance 
and profits; this ultimately guides the decision to otherwise invest, re-evaluate, or abandon the project.

The maintenance policy, schedule, and efficiency of the plant's operations would not typically be a key performance indicator (KPI) or metric for investment decisions under traditional valuation methods. However, the analysis, results, and interpretations lend credence to the conclusion that the real (total) cost of investment is not necessarily a discounted aggregate of determined costs, equipment, products, or employees, but the cognizance of the time, effort, technical ability, resources, and strategy to maintain total plant availability or efficiency at defined levels for maximum profit.

It can therefore be concluded that deriving the true total cost of ownership in project investment or evaluation terms lies in the ability of the investor to adequately consider the equipment, technology, and skilled human capital available or best-suited to manage the proposed venture, based on location and other non-financial or intangible considerations beyond the obvious $\mathrm{kWh}$ or electricity price indices usually evaluated in traditional life cycle costing analyses. Therefore, investment decisions in relation to waste valorization efforts, where the success of an RE project is largely dependent on private investor-operator, modular systems, which tend to perform more efficiently due to stronger technical and financial capacities at their disposal [16], should be evaluated in light of potential destabilizing factors, which erode the long-term value of the project.

The basis of investment, techno-economic, or technology assessments are often to determine the value of technical efficiency and infrastructure investment required to fulfill project objectives. This often ignores significant elements which impact revenue streams and the entire validity of a given project at a future date. Factoring in the time value of costs or 'variable investments' and operational efficiencies allows for a comprehensive evaluation of the project in cognizance of the uncertainty and significant financial risk of investment. The LCI analysis draws vital conclusions for strategic managerial decisionmaking, and its implementation will be constrained in the real world by factors such as the available funds for investment, energy demand metrics, the nature and availability of required biomass feedstock, changes in cost of plants based on market conditions, and changes in subsidies. In this regard, access to energy finance and investment mostly for subSaharan African countries remains imperative, and will equally require national support systems and strategies to ultimately manage political and regulatory risks related to energy infrastructure projects.

The challenges with data collation, access, and availability in Africa generally results in scenarios where theoretical or proxy data is used for research and inference. The results therefore remain cautious estimates which do not necessarily capture empirical realities, but serve as a guide for decision support and planning processes.

\section{Conclusions}

Rural electrification in parts of Africa has proved challenging due to scattered population sites, low consumption levels, bad roads and networks, and low population densities. Renewable energy is therefore expected to play a pivotal role in satisfying an increasing demand for electricity, while equally enabling access to rural energy services. Therefore, future economic development is largely dependent on the creation of sustainable energy systems through enhanced investment in RE conversion systems for the purpose of electricity generation.

A limited scope analysis has been carried out on a previous study, which proposed the development of a 5 MW biopower plant for Nigeria. The LCI analysis was used to evaluate the viability of the proposed power plant through an assessment of the maintenance schedules, break-downs and repair wait times, and overall operational efficiency of equipment required for energy generation purposes. The results show enhanced total performance of the plant by up to $56 \%$ where system availability is increased. It is therefore concluded using pareto principles that the operational efficiency of a power plant, although a minor 
variable in traditional costing methodology, remains a significant metric in overall strategic investment decisions of this magnitude.

Private participation in the RE-based power sector will also be encouraged through policies and programs which insure investor funds while limiting risk exposure, and it is expected that a committed government will consistently pursue the adoption of RE systems in the mainstream energy mix.

In addition, the provision of tax subsidies, secure and investor-friendly environments, structured regulation, and implementation remain significant in the bid to improve Nigeria's energy access metrics as a pre-cursor to achieving the United Nations sustainable development goals (UNSDGs) and ensuring a sustainable energy future for otherwise disenfranchised communities.

Supplementary Materials: The following are available online at https: / www.mdpi.com/article / 10.3390/su14031423/s1, Table S1: Total Performance Indicator at 85\% Availability, Table S2: Total Performance Indicator at 91\% Availability.

Author Contributions: Conceptualization, J.L.-O.; methodology, J.L.-O.; validation, J.L.-O. and D.S. and formal analysis, J.L.-O.; writing-original draft preparation, J.L.-O.; writing-review and editing, J.L.-O. and D.S.; visualization, J.L.-O.; supervision, D.S. and E.N. All authors have read and agreed to the published version of the manuscript.

Funding: This research received no external funding. However, the APC was funded by the African Centre of Excellence in Energy for Sustainable Development (ACE-ESD).

Institutional Review Board Statement: Not applicable.

Informed Consent Statement: Not applicable.

Data Availability Statement: The data that support the findings are available upon request from the corresponding author.

Acknowledgments: The authors wish to acknowledge the platform provided by the African Centre of Excellence in Energy for Sustainable Development (ACE-ESD), which is currently hosted by the College of Science and Technology at the University of Rwanda.

Conflicts of Interest: The authors declare no conflict of interest.

\section{References}

1. Bazmi, A.A.; Zahedi, G.; Hashim, H. Design of decentralized biopower generation and distribution system for developing countries. J. Clean. Prod. 2015, 86, 209-220. [CrossRef]

2. Adeniyi, F. Overcoming the Market Constraints to On-Grid Renewable Energy Investments in Nigeria; Oxford Institute for Energy Studies, OIES PAPER: Oxford, UK, 2019. [CrossRef]

3. Hong, C.S.; Lee, E.B. Power plant economic analysis: Maximizing lifecycle profitability by simulating preliminary design solutions of steam-cycle conditions. Energies 2018, 11, 2245. [CrossRef]

4. Levi-Oguike, J.; Sandoval, D.; Ntagwirumugara, E. Blockchain technology and renewable energy access: A case for sub-Saharan Africa. In Proceedings of the 2019 IEEE 5th International Conference for Convergence Technology I2CT, Bombay, India, 29-31 March 2019; pp. 1-6. [CrossRef]

5. Onyia, C.J.; Agbatah, O.B.; Amasiatu, S.I.; Nnam, L.E.; Enekwenchi, K.K. Waste to Energy Technologies and Its Energy Generation in Nigeria. Int. J. Eng. Mod. Technol. 2020, 6, 40-44.

6. Sobamowo, G.M.; Ojolo, S.J. Techno-economic analysis of biomass energy utilization through gasification technology for sustainable energy production and economic development in Nigeria. J. Energy 2018, 2018, 1-16. [CrossRef]

7. Kaza, S.; Yao, L.C.; Bhada-Tata, P.; Van Woerden, F. What a Waste 2.0. In A Global Snapshot of Solid Waste Management to 2050; World Bank Publications: Washington, DC, USA, 2018. [CrossRef]

8. Ferronato, N.; Torretta, V. Waste mismanagement in developing countries: A review of global issues. Int. J. Environ. Res. Public Health 2019, 16, 1060. [CrossRef]

9. Chen, S.; Feng, H.; Zheng, J.; Ye, J.; Song, Y.; Yang, H.; Zhou, M. Life cycle assessment and economic analysis of biomass energy technology in China: A brief review. Processes 2020, 8, 1112. [CrossRef]

10. Levi-Oguike, J.; Sandoval, D. African biopower investment and policy sufficiency: A qualitative comparative analysis. Int. J. Sustain. Dev. World Ecol. 2021, 1-8. [CrossRef]

11. UN Environment Programme; International Solid Waste Association. Global Waste Management Outlook; UN Environment Programme: Nairobi, Kenya, 2015; ISBN 978-92-807-3479-9 DTI/1957/JA. 
12. Van Zyl-Bulitta, V.H.; Ritzel, C.; Stafford, W.; Wong, J.G. A compass to guide through the myriad of sustainable energy transition options across the global north-south divide. Energy 2019, 181, 307-320. [CrossRef]

13. Olujobi, O.J.; Ufua, D.E.; Olokundun, M.; Olujobi, O.M. Conversion of organic wastes to electricity in Nigeria: Legal perspective on the challenges and prospects. Int. J. Environ. Sci. Technol. 2021, 1-12. [CrossRef]

14. Diaz-Maurin, F.; Chiguvare, Z.; Gope, G. Scarcity in abundance: The challenges of promoting energy access in the Southern African region. Energy Policy 2018, 120, 110-120. [CrossRef]

15. Uchendu, O.H. Household Waste Disposal Laws in the Federal Republic of Nigeria. 2016, p. 57. Available online: http: //scholarworks.gsu.edu/iph_capstone/38 (accessed on 31 July 2021).

16. Cucchiella, F.; D'Adamo, I.; Gastaldi, M. Financial analysis for investment and policy decisions in the renewable energy sector. Clean Technol. Environ. Policy 2015, 17, 887-904. [CrossRef]

17. Brown, M.A.; Favero, A.; Thomas, V.M.; Banboukian, A. The economic and environmental performance of biomass as an 'intermediate' resource for power production. Util. Policy 2019, 58, 52-62. [CrossRef]

18. Bocci, E.; Sisinni, M.; Moneti, M.; Vecchione, L.; di Carlo, A.; Villarini, M. State of art of small scale biomass gasification power systems: A review of the different typologies. Energy Procedia 2014, 45, 247-256. [CrossRef]

19. Baldoni, E.; Coderoni, S.; di Giuseppe, E.; D'orazio, M.; Esposti, R.; Maracchini, G. A software tool for a stochastic life cycle assessment and costing of buildings' energy efficiency measures. Sustainability 2021, 13, 7975. [CrossRef]

20. Snodgrass, K. Life-Cycle Cost Analysis for Buildings Is Easier Than You Thought. 2003. Available online: http://scholar.google. $\mathrm{com} /$ scholar?hl=en\&btnG=Search\&q=intitle:Life-Cycle+Cost+Analysis+for+Buildings+Is+Easier+Than+You+Thought\#1 (accessed on 3 October 2021).

21. Yuan, X.; Chen, L.; Sheng, X.; Liu, M.; Xu, Y.; Tang, Y.; Wang, Q.; Ma, Q.; Tang, Y.; Zou, J. Life cycle cost of electricity production: A comparative study of coal-fired, biomass, and wind power in China Xueliang. Energies 2021, 14, 3463. [CrossRef]

22. Di Francisco, M.R.P.A.P.; Gonzalez Juncà, A.; Gavaldà Torrellas, O. Bioenergy for Sustainable Local Energy Services and Energy Access in Africa Life: Stakeholder Mapping and Literature Review Report. September 2021. Available online: https:/ / www.gov.uk/dfid-research-outputs/bioenergy-for-sustainable-energy-access-in-africa-stakeholder-mapping-andliterature-review-report\#citation (accessed on 5 October 2021).

23. Li, C.; Wang, F.; Zhang, D.; Ye, X. Cost management for waste to energy systems using life cycle costing approach: A case study from China. J. Renew. Sustain. Energy 2016, 8, 025901. [CrossRef]

24. Myskova, R.; Spickova, M. Costs efficiency evaluation using life cycle costing as strategic method. Procedia Econ. Financ. 2015, 34, 337-343. [CrossRef]

25. Andersson, C.; Kianian, B.; Kurdve, M. Comparing life cycle costing and performance part costing in assessing acquisition and operational cost of new manufacturing technologies. In Proceedings of the 26th CIRP Conference on Life Cycle Engineering, West Lafayette, IN, USA, 7-9 May 2019; pp. 428-433. Available online: www.elsevier.com/locate/procedia (accessed on 5 October 2021).

26. Kurdve, M.; Bengtsson, M. Machining equipment life cycle costing model with dynamic maintenance cost. In Proceedings of the 23rd CIRP Conference on Life Cycle Engineering, Berlin, Germany, 22-24 May 2016; pp. 102-107. [CrossRef]

27. Dulcic, Z.; Katicic, L.; Lisjak, D. Asset governance as strategy for physical asset. In Proceedings of the 7th International Conference of the School of Economics and Business, Sarajevo, Bosnia and Herzegovina, 13-14 September 2014; pp. 208-221. Available online: https:/ / www.bib.irb.hr/728091 (accessed on 5 October 2021).

28. Stimie, J.E.; Vlok, P.J. A mechanism for the early detection and management of physical asset management strategy execution failure. South African J. Ind. Eng. Novemb. 2016, 27, 158-173. [CrossRef]

29. Eicher, B. Selection of asset investment models by hospitals: Examination of influencing factors, using Switzerland as an example. Int. J. Health Plann. Manage. 2016, 31, 554-579. [CrossRef]

30. Raposo, H.; Farinha, J.T.; Ferreira, L.; Galar, D. Dimensioning reserve bus fleet using life cycle cost models and condition based/predictive maintenance-A case study. Public Transp. 2018, 10, 1-22. [CrossRef]

31. Raposo, H.; Farinha, J.T.; Ferreira, L.; Galar, D. An integrated econometric model for bus replacement and spare reserve based on a condition predictive maintenance model. Maint. Reliab. Eksploatacja Niezawodnosc Maint. Reliab. 2017, 19, 358-368. [CrossRef]

32. Farinha, J.T.; Galar, D.; Raposo, H. Life cycle cost versus life cycle investment-A new approach. WSEAS Trans. Syst. Control 2020, 15, 743-753. [CrossRef]

33. Toyese, O.; Jibiril, B.E.Y. Design and feasibility study of a 5MW bio-power plant in Nigeria. Int. J. Renew. Energy Res. 2016, 6, 1496-1505. [CrossRef] 